\title{
Activated Coagulation Time
}

National Cancer Institute

\section{Source}

National Cancer Institute. Activated Coagulation Time. NCI Thesaurus. Code C103348.

The determination of the amount of the inhibition of blood coagulation in response to anticoagulant therapies. 